\title{
Awareness due to vaporizer malfunction
}

\author{
R Kulasiri ${ }^{1}$, HKB Wilgamuwa ${ }^{2 *}$, \\ Consultant Anaesthetist ${ }^{1}$, Registrar in Anaesthesiology ${ }^{2 *}$, National Hospital of Sri Lanka, Colombo, \\ Sri Lanka.
}

\begin{abstract}
Accidental awareness during anaesthesia is multifactorial. Despite the cause it is harmful to both the patient and the anaesthetist. This case report is of a 68-year-old ASA 1 lady coming for a routine plastic surgery who had experienced accidental awareness under anaestheisa due to a faulty vaporizer. Timely detection and intervention may have prevented the long-term harmful sequalae of accidental awareness to the patient.
\end{abstract}

Keywords: awareness; vaporizer malfunction; post-traumatic stress disorder; MAC monitoring; anaesthesia depth monitoring

\section{Introduction}

Intraoperative awareness is a distressing complication to the patient with long-term adverse sequalae such as post-traumatic stress disorder and it may raise litigation problems to the anaesthetist. Here we present a case of intraoperative awareness due to malfunction of the vaporizer.

\section{Case presentation}

A 68 -year-old female patient (body weight $58 \mathrm{~kg}$, BMI $26.7 \mathrm{~kg} / \mathrm{m}^{2}$ ) was scheduled for reconstruction of a large scalp defect under general anaesthesia (GA). She was attacked by a dog, five days previously and sustained the scalp injury and right upper arm injury for which she had undergone primary wound suturing under GA without any complications. There was no significant medical or allergic history. Clinical examination and perioperative investigations were normal apart from low haemoglobin levels $(8.5 \mathrm{~g} / \mathrm{dl})$ for which adequate red cell concentrate was reserved. Premedication was with oral famotidine $20 \mathrm{mg}$ and metoclopramide $10 \mathrm{mg}$, two doses since she had mild dyspeptic symptoms. Paracetamol $1 \mathrm{~g}$ was given orally $2 \mathrm{hrs}$ before the surgery as a preemptive analgesic. Patient was

\footnotetext{
*Correspondence: HKB Wilgamuwa

E mail: harshana.kanishka@gmail.com

iD https://orcid.org/0000-0002-3322-9894

Received: 01/09/2017

Accepted: 20/09/2017

DOI: http://doi.org/10.4038/slja.v26i1.8275
}

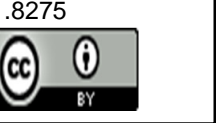

kept fasting according to AAGBI guidelines. Informed written consent was obtained.

Anaesthetic machine, pipeline gas supply, breathing circuit, ventilator, difficult airway trolley and emergency resuscitation equipment were checked preoperatively. When checking the vaporizer included to the breathing circuit, there was about a $5 \mathrm{~mm}$ dip observed when common gas outlet was occluded.

Multipara monitor was applied and baseline readings were taken. Her initial non-invasive blood pressure (NIBP), heart rate(HR) and on-air oxygen saturation $\left(\mathrm{SpO}_{2}\right)$ were $135 / 67 \mathrm{mmHg}, 86$ beats per minute (bpm) and 99\% respectively. Intravenous (iv) access was taken in the left hand with a 20G cannula. Cefuroxime $1.5 \mathrm{~g}$ and metronidazole $500 \mathrm{mg}$ were given i.v. as prophylactic antibiotics.

WHO surgical checklist was performed. Preoxygenation was done with $100 \%$ oxygen for $3 \mathrm{mins}$ and anaesthesia was induced with morphine $6 \mathrm{mg}$, propofol $120 \mathrm{mg}$ i.v. Atracurium $40 \mathrm{mg}$ was given after checking the ability to bag mask ventilate and $1.5 \%$ isoflurane in oxygen $6 \mathrm{~L} / \mathrm{min}$ was continued for $3 \mathrm{~min}$. Laryngoscopy was performed (Cormack-Lehane view II) and trachea was intubated with reinforced cuffed endotracheal tube (ID $7.5 \mathrm{~mm}$ ) which was anchored at lip level length of $18 \mathrm{~cm}$ after confirming bilateral equal air entry and capnography trace. Dexamethasone $8 \mathrm{mg}$ was given i.v. as an antiemetic.

Anaesthesia was maintained with $1 \%$ isoflurane, oxygen $1 \mathrm{~L} / \mathrm{min}$ and nitrous oxide $2 \mathrm{~L} / \mathrm{min}$. She was connected to accoma ventilator with tidal 
volume of $300 \mathrm{ml}$, ventilator rate of $12 / \mathrm{min}$ and I:E ratio of 1:2. Patient was positioned prone and bilateral equal air entry was confirmed. Patient warming device was applied.

Intraoperative monitoring of electrocardiogram (ECG), heart rate, NIBP, temperature, end tidal carbon dioxide $\left(\mathrm{ETCO}_{2}\right)$ was continued throughout. End tidal oxygen and inhalational vapour analyzers, neuromuscular blockade monitor and bispectral index (BIS) were not available.

It took about 30mins since the induction of anaesthesia to start surgery after positioning and preparation of surgical site. $15 \mathrm{mins}$ after induction gradual increase in heart rate and blood pressure were noted; she was not hypoxic nor hypercarbic. Despite the increase of isoflurane concentration to $2.5 \%$ and giving fentanyl $50 \mathrm{mcg}$ and atracurium $10 \mathrm{mg}$ i.v., tachycardia and hypertension worsened. Soon after surgical incision HR was around $125 \mathrm{bpm}$ while NIBP was 207/110mmHg. At that point propofol $50 \mathrm{mg}$ i.v. bolus was given and it was decided to start an antihypertensive. But following propofol bolus HR and NIBP became normalized. Light plane of anaesthesia and possible awareness was suspected since patient only responded well to hypnotic. Propofol $100 \mathrm{mg} / \mathrm{h}$ i.v. infusion was started and continued throughout surgery.

Surgery lasted for 3.5hrs. Blood loss was around $100 \mathrm{ml}$ and $1 \mathrm{~L}$ of crystalloids was transfused. Her intraoperative parameters following propofol infusion were as follows: HR $81-102 \mathrm{bpm}, \mathrm{ECG}$ - sinus rhythm, systolic BP $105-139 \mathrm{mmHg}$, diastolic BP 79-91mmHg, $\mathrm{EtCO}_{2} 35-41 \mathrm{mmHg}$ and $\mathrm{SPO}_{2} 98-100 \%$.

Morphine $3 \mathrm{mg}$ i.v. was repeated during surgery and ondansetron $8 \mathrm{mg}$ was given i.v. towards the end of surgery. At the end of surgery residual neuromuscular blockade was reversed with neostigmine $2.5 \mathrm{mg}$ and atropine $1.2 \mathrm{mg}$ i.v. Awake extubation was done, recovery was uneventful and she was sent back to the ward.

Next morning, on inquiry she revealed that at the beginning of the surgery until her head was shaved and surgery was started, she was aware that surgery was going on. She was not scared as there was no pain and after some time it had disappeared. Next, she remembered the extubation. Further she had explicit recall of conversations of surgical room personnel at the initial part of the surgery suggestive of intra operative awareness. She was explained and counselled regarding intraoperative awareness and no psychological problem was identified after one week of surgery.

On detailed examination of the anaesthetic machine by biomedical engineer, malfunction of the isoflurane vaporizer was identified. The vaporizer did not deliver the correct vapour concentration indicated in the dial due to the defect. It was repaired and recalibrated correctly.

\section{Discussion}

Awareness is said to occur when there is inadequate anaesthetic vapour delivered to the brain resulting in inadequate depth of anaesthesia. It can be either explicit awareness or implicit awareness. Explicit awareness is conscious recollection of intraoperative events either spontaneously or when directly questioned; whereas implicit awareness denotes memories that exist without conscious recall of the patient but they can alter patient's subsequent behavior following the event. The incidence of awareness in UK is estimated to be $0.1-0.2 \%$.

In this case, accidental explicit awareness occurred due to the faulty vaporizer which was not detected during conventional anaesthetic machine check. Other contributory factors were scarcity of resources such as vapour analysis and depth of anaesthesia monitoring (i.e. BIS). But it was diagnosed early with cardiovascular changes of tachycardia and hypertension and suspicion. Other physiological responses like pupillary reactions and lacrimation were not seen as head was covered with drapes. The use of neuromuscular blocking agents may have contributed to late detection.

\section{Conclusion}

Vaporizer malfunction may not be detected during conventional anaesthetic machine check and it is recommended to have regular vaporizer service checks and calibrations. Further, at least vapour analysis and MAC monitoring (0.8-1.0) should be used when anaesthetizing patients using inhalational agents to minimize intraoperative awareness. 
Wilgamuwa et al. Sri Lankan Journal of Anaesthesiology: 26(1):61-63(2018)

\section{Consent}

Consent was obtained directly from the patient to allow for discussion and review of her case in this case report.

\section{Declaration of interest}

None

\section{References}

1. Goddard N, Smith D. Unintended awareness and monitoring of depth of anaesthesia. Contin Educ Anaesth Crit Care Pain 2013;13(6): 213-217.

https://doi.org/10.1093/bjaceaccp/mkt016

2. Hardman JG, Aitkenhead AR. Awareness during anaesthesia. Contin Educ Anaesth Crit Care Pain 2005;5(6):183-186

https://doi.org/10.1093/bjaceaccp/mki049

3. Niranjan N, Wilson I. Awareness under anaesthesia. Anaesthesia tutorial of the week 108. 